Click www.researchjournal.co.in/online/subdetail.html to purchase.

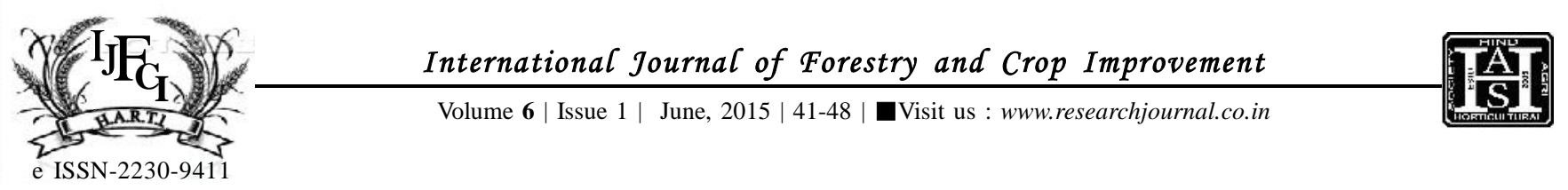

RESEARCH ARTICLE

DOI: $10.15740 / \mathrm{HAS} / \mathrm{IJFCI} / 6.1 / 41-48$

\title{
Cost of cultivation of sugarcane crop in Meerut district of Uttar Pradesh
}

\author{
KRISHNA Kant, SidDharth PraKash TRIPATHI and MaMtaMEena
}

\begin{abstract}
Sugarcane is an important agro industry crop in India plays a pivotal role in national economic by contributing 1.9 per cent to gross domestic product, form an important component in cropping pattern of the sugarcane growers, provide an essential commodity in the form of sugar and jiggery and solves the problem of green fodder for half of the year. The crop is cultivated in 5.03 million hectare producing more than 342 million tones with a productivity of about 70 tonnes per hectare. In India, Uttar Pradesh contributes about 47 per cent in area (1.98 million hectare) and production (117.14 million tonnes) with 47.36 per cent of total sugarcane production. The present study was attempt on, to work out the cost and returns of sugarcane production for different size group of farms in the study area. From the purposively selected district and block on the basis of highest area under the crop. Four villages were selected randomly from the selected block, a complete list of the farmers were prepared and than categorized into four categories i.e. marginal, small, medium and large. From the total sugarcane growers, 100 respondents were selected in probability proportion to their population, for the collection of data, suitable statistical tools were employed to meet the above objective. The cost of cultivation of sugarcane planted was Rs. 172679, in which share of operational cost, land rent and material costs was 38, 22 and 26 per cent, respectively. The cost of cultivation of sugarcane ratoon was to be Rs. 129752.65 with share of operational cost, land rent and material cost of 41, 29 and 14 per cent, respectively.
\end{abstract}

KEY WORDS : Cost, Cultivation, Sugarcane crop

How TO CITE THIS ARTICLE : Kant, Krishna, Tripathi, Siddharth Prakash and Meena, Mamta (2015). Cost of cultivation of sugarcane crop in Meerut district of Uttar Pradesh. Internat. J. Forestry \& Crop Improv., 6 (1) : 41-48.

Article Chronical : Received : 16.01.2015; Revised : 21.04.2015; Accepted : 24.05.2015 